\title{
Critical appraisal of ticagrelor in the management of acute coronary syndrome
}

This article was published in the following Dove Press journal:

Therapeutics and Clinical Risk Management

2 December 201 I

Number of times this article has been viewed

\author{
James J Nawarskas \\ Stanley S Snowden \\ University of New Mexico College \\ of Pharmacy, Albuquerque, NM, USA
}

Correspondence: James J Nawarskas University of New Mexico College of Pharmacy, MSC09 5360 I University of New Mexico, Albuquerque, NM 87I3I-000I, USA

Tel +l 5052720584

Fax + I 5052726749

Email jnawarskas@salud.unm.edu
Abstract: Ticagrelor is a novel $\mathrm{P}_{2} \mathrm{Y}_{12}$ receptor antagonist which, like clopidogrel and prasugrel, functions by blocking adenosine diphosphate-mediated platelet aggregation. However, unlike the aforementioned agents, the binding of ticagrelor to this receptor is reversible. Ticagrelor is also believed to mediate some of its beneficial effects by augmenting the effects of adenosine, which is another unique pharmacologic property of this drug. In terms of antiplatelet effect, ticagrelor is more potent than clopidogrel and produces a faster and stronger inhibition of platelet aggregation. This may also be an advantage of ticagrelor over prasugrel, but this has not been adequately studied. Due to the reversible nature of the binding of ticagrelor to the platelet receptor, ticagrelor has a relatively fast offset of effect, with platelet aggregation approaching pretreatment levels about 3 days after discontinuation of therapy. This has advantages in patients requiring invasive procedures, but also makes medication adherence very important in order to be able to maintain an effective antiplatelet effect. Ticagrelor has been shown to be clinically superior to clopidogrel when given to patients with an acute coronary syndrome, resulting in significantly lower rates of myocardial infarction and vascular death. However, ticagrelor is indicated to be administered with aspirin, and the clinical benefits of ticagrelor may be less when daily dosages of aspirin exceed $100 \mathrm{mg}$. As expected, bleeding is the most common adverse effect with ticagrelor, although it occurs at rates comparable with those seen for clopidogrel with the exception of noncoronary artery bypass graft-related major bleeding and fatal intracranial bleeds, the latter of which occurs only rarely. Dyspnea is another common adverse effect with ticagrelor, although this is usually not severe and resolves with drug discontinuation. Unlike clopidogrel, there are no known pharmacogenomic concerns with ticagrelor, and emerging data suggest ticagrelor to be effective in patients resistant to clopidogrel, although more study is needed on this topic. While preliminary data suggest ticagrelor to be cost effective when compared with generic clopidogrel, the acquisition cost of ticagrelor is not insignificant and this will likely be an issue for many health care organizations. Currently, ticagrelor is well positioned to assume an active role in the treatment of coronary artery disease due to an impressive efficacy profile and reasonable safety. Its ultimate role in therapy will continue to evolve as studies on this drug continue eg, (Prevention of Cardiovascular Events in Patients with Prior Heart Attack Using Ticagrelor Compared to Placebo on a Background of Aspirin, PEGASUS) and more information hopefully becomes available on its use in clopidogrel nonresponders and relative safety and efficacy compared with prasugrel.

Keywords: ticagrelor, $\mathrm{P} 2 \mathrm{Y}_{12}$, adenosine receptor antagonist

\section{Introduction}

Patients with acute coronary syndromes (ACS) have high platelet activation which leads to thrombus formation and myocardial ischemia. ${ }^{1}$ Platelets have numerous 
ways of becoming activated, so there are numerous targets for drugs which inhibit platelet function. Current antiplatelet agents available to clinicians for treating and preventing ACS include aspirin, glycoprotein IIb/IIIa receptor antagonists (tirofiban, abciximab, and eptifibatide), thienopyridines (clopidogrel and prasugrel), and ticagrelor. Aspirin inhibits cyclo-oxygenase-1 in platelets, which decreases thromboxane A2 concentrations. While aspirin reduces thrombotic events, stroke, and myocardial infarction by approximately 20\%-25\% through decreased platelet activation, this drug results in only partial inhibition of platelet aggregation (IPA)., ${ }^{2,3}$ This has led to the use of other antiplatelet drugs with different mechanisms of action in addition to aspirin. Secondary prevention of recurrent thrombotic episodes sometimes requires the use of two antiplatelet agents with different mechanisms of action, ie, dual antiplatelet therapy. Dual antiplatelet therapy is now considered standard of care for patients with ACS with or without stenting. ${ }^{4,5}$

Thienopyridines (clopidogrel and prasugrel) work by covalently and irreversibly binding to the adenosine diphosphate (ADP) site on the $\mathrm{P} 2 \mathrm{Y}_{12}$ receptor, thereby preventing ADP-mediated platelet aggregation for the life of the platelet (Figure 1). The most utilized drug in this class is clopidogrel which has been shown to be beneficial in patients with ACS regardless of whether or not percutaneous coronary intervention is performed. ${ }^{6,7}$ Clopidogrel is a prodrug which needs to be converted to an active metabolite via hepatic activation mainly through cytochrome P450 (CYP) 2C19 and 3A4. This leads to delayed antiplatelet activity and potential interpatient variability because of genetic polymorphisms in CYP2C19, leading to increased or decreased activity of this enzyme. Prasugrel is also a prodrug which requires hepatic activation but, unlike clopidogrel, this drug is activated much faster

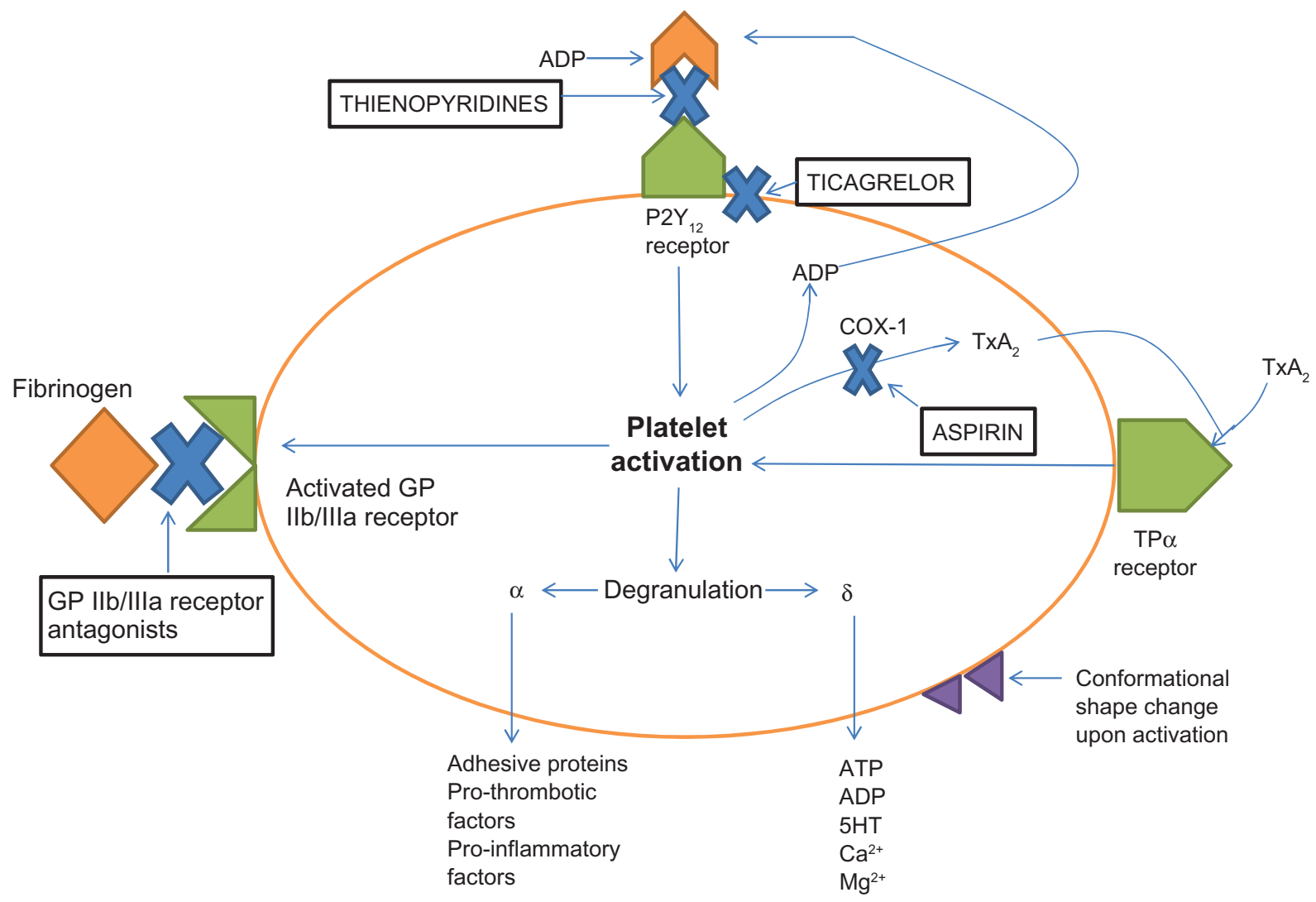

Figure I Adenosine diphosphate (ADP) binds to the $\mathrm{P} 2 \mathrm{Y}_{12}$ receptor. This binding results in activation of the platelet which causes a conformational shape change, activation of the glycoprotein (GP) Ilb/llla receptors, and platelet aggregation. Ticagrelor binds at a site on the P2Y 12 receptor that is separate from the ADP binding site and produces a non-competitive inhibition, while the thienopyridines, clopidogrel and prasugrel, bind directly to the ADP binding site on the P2Y $Y_{12}$ receptor permanently blocking this site. Antiplatelet agents that block the $\mathrm{P}_{2} \mathrm{Y}_{12}$ receptor have complementary effects with aspirin in terms of platelet inhibition because their mechanism of action is different than that of aspirin, which blocks cyclo-oxygenase-I causing a decrease in thromboxane A2.

Abbreviations: 5HT, 5-hydroxytryptamine; $\alpha$, alpha granules; $\delta$, dense granules; ADP, adenosine diphosphate; ATP, adenosine triphosphate; COX-I, cyclo-oxygenase-I; GP, glycoprotein; TP $\alpha$, thromboxane $A 2$ receptor; TxA2, thromboxane A2. 
and has better IPA. Studies have shown greater efficacy as well as more bleeding risk with prasugrel compared with clopidogrel. $^{8}$

Ticagrelor is chemically, pharmacologically, and pharmacokinetically different to the thienopyridines (Figure 2). This article will review the current literature surrounding the pharmacology, pharmacokinetics, clinical outcomes, adverse events, and practical therapeutic considerations with ticagrelor.

A literature search was conducted as recently as September 2011 using PubMed with the following search terms: "ticagrelor," "Brilinta," "PLATO trial," "pharmacokinetics," "pharmacodynamics," "platelet aggregation," "platelet activation", and "antiplatelet drugs." These terms were cross-referenced with each other. The literature search was only limited to articles published in English. There were no other limits so that a larger amount of studies could be collected and analyzed for utility. Additional articles were found by reviewing and cross-checking the references of relevant articles. Product package inserts and some other product-specific information were obtained from the manufacturers' individual websites. The United States Food and Drug Administration website (fda.gov) was also reviewed for pertinent information.

\section{Clopidogrel:}<smiles>COC(=O)[C@H](NC1Cc2ccsc2C1)c1ccccc1Cl</smiles>

Ticagrelor:

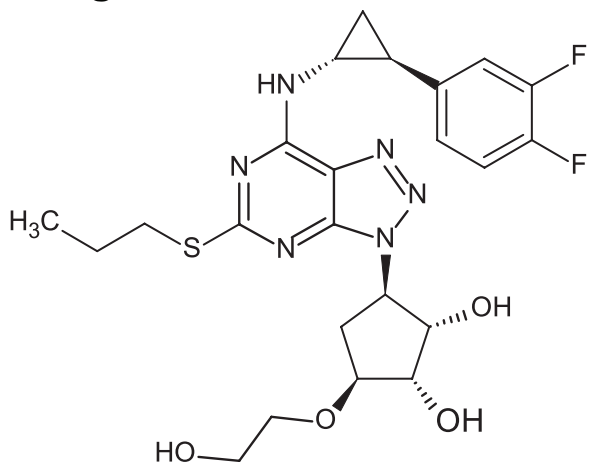

Figure 2 Chemical structures of clopidogrel, prasugrel, ticagrelor, and adenosine.

\section{Pharmacology}

ADP is a potent chemical stimulator of platelet activation. ADP binds to and activates two different G-protein coupled receptors, $\mathrm{P} 2 \mathrm{Y}_{1}$ and $\mathrm{P} 2 \mathrm{Y}_{12}$. Activation of the $\mathrm{P} 2 \mathrm{Y}_{1}$ receptor leads to reversible platelet aggregation and shape change, while activation of the $\mathrm{P} 2 \mathrm{Y}_{12}$ receptor leads to a slower platelet aggregation that is more sustained and is not involved in any shape change. Both of these receptors need to be activated by ADP at the same time to elicit a typical platelet aggregation response. ${ }^{9}$ Of the two receptors, $\mathrm{P} 2 \mathrm{Y}_{12}$ is more tissue-selective, which makes this receptor an ideal target for drug therapy. ${ }^{9}$

Both the thienopyridines and ticagrelor are $\mathrm{P} 2 \mathrm{Y}_{12}$ receptor antagonists. Ticagrelor is not a thienopyridine, but rather belongs to a new class of $\mathrm{P} 2 \mathrm{Y}_{12}$ receptor inhibitors known as cyclopentyl-triazolo-pyrimides. This drug is a very selective antagonist for the $\mathrm{P}_{2} \mathrm{Y}_{12}$ receptor on platelets and, unlike the thienopyridines, binds reversibly to this receptor. Also, unlike clopidogrel or prasugrel, ticagrelor allows ADP to bind to the $\mathrm{P} 2 \mathrm{Y}_{12}$ receptor because this drug binds on a site that is distant from the ADP site on the $\mathrm{P}_{2} \mathrm{Y}_{12}$ receptor (Figure 1). This noncompetitive inhibition blocks the conformational change of this receptor which is responsible for downstream activation of platelet aggregation. ${ }^{10}$ When ticagrelor leaves

\section{Prasugrel:}<smiles>CC(=O)Oc1cc2c(s1)CCN(C(C(=O)C1CC1)c1ccccc1F)C2</smiles>

\section{Adenosine:}<smiles>Nc1ncnc2c1ncn2[C@@H]1OC(CO)[C@@H](O)[C@H]1O</smiles> 
the site on the $\mathrm{P} 2 \mathrm{Y}_{12}$ receptor it does not alter the receptor which allows it to engage in conformational changes according to the appropriate stimuli, such as ADP binding.

Ticagrelor has additional benefits beyond the inhibition of $\mathrm{P} 2 \mathrm{Y}_{12}$ receptors on platelets. These $\mathrm{P} 2 \mathrm{Y}_{12}$ receptors are also found in vascular smooth muscle which mediates vasoconstriction. Ticagrelor has the ability to enter the smooth muscle of the vasculature and inhibit local $\mathrm{P} 2 \mathrm{Y}_{12}$ receptors, thereby causing vasodilation. This ability to inhibit $\mathrm{P} 2 \mathrm{Y}_{12}$ receptors in the vascular smooth muscle is unique to ticagrelor. ${ }^{10}$ Another additional benefit of ticagrelor has to do with the ability of this drug to augment the effects of endogenous adenosine. During ACS, adenosine is released, which serves several beneficial functions, one of which is to increase coronary blood flow. There is typically an accumulation of adenosine in response to tissue ischemia and injury which occurs during ACS. Adenosine also acts as an anti-inflammatory and cardioprotective agent by improving preconditioning and postconditioning and preventing sudden death. ${ }^{11}$ The chemical structure of ticagrelor is very similar to that of adenosine (Figure 2). It is theorized that ticagrelor loses two key structures after oral administration, ie, propyl sulfate and benzodifluoride, by either oxygenase and/or radical fragmentation pathways. In this sense, ticagrelor is effectively a precursor of adenosine because, after the loss of these structures, the resulting compound is essentially adenosine. ${ }^{11}$ Ticagrelor also inhibits uptake of adenosine by erythrocytes during ACS. The mechanism for this is thought to be inhibition of the sodiumindependent equilibrative nucleoside transporters subtype 1. This transporter regulates the influx and efflux of adenosine particularly in cardiac myocytes. ${ }^{12}$ This adenosine uptake inhibition appears to be dose-dependent and is 30-50-fold less potent compared with its ability to inhibit platelets. ${ }^{10,13}$ This results in augmentation of the coronary blood flow induced by adenosine by prolonging its half-life and increasing systemic exposure to this agent. ${ }^{10,13}$

\section{Pharmacokinetics}

Findings from pharmacokinetic studies in healthy volunteers and patients with atherosclerosis have provided most of the pharmacokinetic information available for ticagrelor. ${ }^{14-17}$ Ticagrelor is only available by the oral route and, at doses ranging from 100 to $400 \mathrm{mg}$ per day, has rapid absorption from the gastrointestinal tract with peak plasma concentrations being achieved in a median of 1.5 hours and 3 hours for the parent compound and active metabolite (AR-C124910XX), respectively. ${ }^{17}$ Inhibition of platelet aggregation of $80 \%-90 \%$ is seen within 2-4 hours after a single oral dose of ticagrelor of $180 \mathrm{mg} .{ }^{15}$ The IPA is dose-dependent; however there is very little increase in IPA with doses greater than $100 \mathrm{mg}$ twice daily. ${ }^{16,17}$ The half-lives of the parent drug and active metabolite are 8 and 12 hours, respectively. This, along with the reversible effects of the drug on platelet aggregation, necessitates twice daily dosing for ticagrelor. At 24 hours after a single ticagrelor dose of $300 \mathrm{mg}$ and $400 \mathrm{mg}$, the mean IPAs were $75 \%$ and $85 \%$, respectively. ${ }^{16}$ The IPAs achieved by ticagrelor were higher than the IPA typically seen with clopidogrel, which is around 50\%. ${ }^{18}$ Pharmacokinetic studies have shown that ticagrelor is mainly restricted to the plasma space, which is where it will interact with platelets and the smooth muscle of the vasculature. ${ }^{16}$ Ticagrelor is primarily metabolized hepatically by CYP3A4 and CYP3A5. Therefore, ticagrelor metabolism, blood levels, and ultimately pharmacologic effects, may be affected by other medications (eg, ketoconazole) or substances (eg, St John's wort) that inhibit or induce CYP3A4 and/or 3A5 enzymes. While ticagrelor does not need to be bioactivated to inhibit platelet aggregation there is one active metabolite, ie, AR-C124910XX. The two enzymes most responsible for the production of this sole active metabolite are CYP3A4 and CYP3A5. ${ }^{19}$ This active metabolite has plasma concentrations that are approximately one third that of its parent compound and is considered to be equipotent in terms of antiplatelet effects. Ticagrelor appears to inhibit CYP2C9 moderately and induce CYP2B6 weakly. ${ }^{19}$ Ticagrelor is mainly excreted in the feces with very little of the parent drug and active metabolite $(<0.05 \%)$ excreted unchanged in the urine. Therefore, no dosage adjustment is needed in patients with kidney dysfunction. ${ }^{20}$ Ticagrelor has also been studied in volunteers with mild hepatic impairment. ${ }^{21}$ The mean maximum concentration, area under the curve, and half-live of ticagrelor and its active metabolite were higher in volunteers with Child-Pugh class A compared with healthy volunteers but these differences are unlikely to be clinically significant and therefore no dosage adjustment is necessary in patients with mild liver dysfunction. There have been no studies looking at moderate (Child-Pugh B) or severe (Child-Pugh C) hepatic dysfunction. The prescribing information for ticagrelor does not provide specific dosing recommendations in patients with moderate hepatic impairment and states that the drug is contraindicated in patients with severe hepatic impairment. ${ }^{20}$

\section{Comparative antiplatelet effects of ticagrelor and clopidogrel}

The Dose confIrmation Study assessing antiPlatelet Effects of AZD6140 versus clopidogRel in non-ST-segment 
Elevation myocardial infarction (DISPERSE) evaluated the pharmacodynamics, pharmacokinetics, safety, and tolerability of various dosages of ticagrelor (AZD6140) versus clopidogrel in patients receiving aspirin therapy. ${ }^{17}$ This was a randomized, double-blind, parallel-group study conducted in patients with known atherosclerotic disease. The dosages of ticagrelor were $50 \mathrm{mg}$ twice daily $(\mathrm{n}=41), 100 \mathrm{mg}$ twice daily $(\mathrm{n}=39), 200 \mathrm{mg}$ twice daily $(n=37)$, or $400 \mathrm{mg}$ once daily $(\mathrm{n}=46)$ and the dose of clopidogrel was $75 \mathrm{mg}$ once daily $(\mathrm{n}=37)$. Treatments were given for 28 days and all patients received aspirin 75-100 mg once daily. Platelet aggregation was analyzed via optical aggregometry of platelet-rich plasma taken from blood samples of the patients at times 0 (predose), 2, 4, 8, and 12 hours (post-dose) on days 1, 14, and 28 and post-dose at 24 hours on days 14 and 28. The IPA was measured using $20 \mu \mathrm{M}$ ADP as the agonist. The safety of the trial medication was assessed by reports of adverse events, including bleeding. The results showed ticagrelor at dosages of $100 \mathrm{mg}$ twice daily, $200 \mathrm{mg}$ twice daily, and $400 \mathrm{mg}$ once daily inhibited ADP-induced platelet aggregation to a greater extent compared with either clopidogrel or ticagrelor $50 \mathrm{mg}$ twice daily. The three higher dosages of ticagrelor did not differ from each other in terms of mean IPA. With this increase in IPA, there was also an increase in bleeding with ticagrelor compared with clopidogrel. Most of the bleeding events were considered to be mild to moderate in severity. There was one major bleed in the ticagrelor group (400 mg once daily) that was gastrointestinal in nature. There was also an increased incidence of dyspnea in the ticagrelor group compared with the clopidogrel group which appeared to be dose-dependent, occurring with greatest severity in the patients receiving $400 \mathrm{mg}$ once daily. The severity of dyspnea varied from mild to moderate, with a total of 29 reported instances of dyspnea, 21 of which were considered mild and eight were considered to be moderate.

Clopidogrel is the classic thienopyridine and the most popular nonaspirin antiplatelet agent used today. However, there are several limitations of clopidogrel therapy, mostly related to interpatient variability in pharmacologic effects. A substudy of the PLATelet inhibition and patient Outcomes (PLATO) trial (ie, PLATO PLATELET) showed ticagrelor to have greater and more consistent platelet inhibition than clopidogrel and did not increase the risk of bleeding. ${ }^{22}$ The two cohorts that were evaluated in this substudy were 69 patients who had received either clopidogrel (300-600 mg loading dose followed by $75 \mathrm{mg}$ per day) or ticagrelor (180 mg loading dose followed by $90 \mathrm{mg}$ twice a day) for at least 28 days and 24 patients who had not received the study medication and have not received clopidogrel treatment within the previous 14 days. The three methods that were used to study platelet aggregation were light transmittance aggregometry (LTA), the VerifyNow P2 ${ }_{12}$ assay (Accumetrics, Inc, San Diego, CA), and vasodilator-stimulated phosphoprotein. The LTA method uses ADP to stimulate platelet aggregation in ex vivo blood samples. A higher response to ADP (measured in $\mu \mathrm{M}$ ) indicates more platelet aggregation. The VerifyNow P2 $Y_{12}$ assay evaluates baseline platelet function through the thrombin receptor-activating peptide channel and the combination of ADP and prostaglandin $\mathrm{E}_{1}$. The ADP is used to activate platelets through interaction with $\mathrm{P} 2 \mathrm{Y}_{1}$ and $\mathrm{P} 2 \mathrm{Y}_{12}$ receptors, while prostaglandin $\mathrm{E}_{1}$ is used to suppress ADP platelet activation via the $\mathrm{P} 2 \mathrm{Y}_{1}$ receptor. A percent change is calculated from the baseline platelet function and results reported using $\mathrm{P} 2 \mathrm{Y}_{12}$ reaction units. The threshold of $>235$ $\mathrm{P} 2 \mathrm{Y}_{12}$ reaction units has been determined to be associated with an increased ischemic risk. Vasodilator-stimulated phosphoprotein measures the platelet reactivity index in which a threshold of $>50 \%$ was determined to be associated with an increased ischemic risk. In all three studies of platelet aggregation, ticagrelor showed more suppression of platelets than clopidogrel in both peak and trough plasma concentrations. Loading doses of ticagrelor showed more platelet inhibition at one hour compared with clopidogrel.

Ticagrelor is not a prodrug and does not have to be metabolically activated to have an antiplatelet effect, while clopidogrel is a prodrug which needs to be activated before eliciting a pharmacologic effect. The bioactivation of clopidogrel occurs in two sequential steps in the liver, with one pathway going through the CYP system, particularly CYP2C19. Once clopidogrel is activated by this enzyme, the active metabolite can inhibit platelets. This bioactivation of clopidogrel takes time and is evident even with loading doses of clopidogrel. A loading dose of clopidogrel significantly shortens the time to achieve maximal IPA; without a loading dose, it takes approximately 5 days to reach maximal IPA with clopidogrel $75 \mathrm{mg}$ once daily. ${ }^{23}$ With $300 \mathrm{mg}$ and $600 \mathrm{mg}$ loading doses of clopidogrel, it takes about 4-8 hours to reach the final extent of platelet aggregation inhibition (ie, IPA observed at the end of the platelet aggregation response), which is about $30 \%$ and $45 \%-50 \%$, respectively, for the $300 \mathrm{mg}$ and $600 \mathrm{mg}$ doses of clopidogrel. ${ }^{15,24}$ This is in comparison with ticagrelor in which the final IPA of $80 \%-90 \%$ is reached approximately $2-4$ hours after a $180 \mathrm{mg}$ loading dose (Table 1). ${ }^{15,24}$

The ONSET/OFFSET study was a randomized, multicenter, double-blind trial to evaluate the time to onset and offset of antiplatelet effects of ticagrelor $90 \mathrm{mg}$ given twice 
Table I Comparison of $\mathrm{P} \mathrm{Y}_{12}$ receptor inhibitors ${ }^{15,20,24,26,58}$

\begin{tabular}{|c|c|c|c|c|c|c|}
\hline Drug & Bioactivation & $\begin{array}{l}\text { Receptor } \\
\text { binding }\end{array}$ & $\begin{array}{l}\text { Maximum } \\
\text { IPA (\%)* }\end{array}$ & $\begin{array}{l}\text { Time to maximum } \\
\text { IPA (hours)* }\end{array}$ & $\begin{array}{l}\text { Half-life of active } \\
\text { drug (hours) }\end{array}$ & $\begin{array}{l}\text { Offset of antiplatelet } \\
\text { action (days) }{ }^{\dagger}\end{array}$ \\
\hline Ticagrelor & No & Reversible & $80-90$ & $2-4$ & $8-12$ & 3 \\
\hline Prasugrel & Yes, one step P-450 activation & Irreversible & $75-80$ & $2-4$ & $7^{\S}$ & $5-7$ \\
\hline Clopidogrel & Yes, two step P-450 activation & Irreversible & $30-50$ & $4-8$ & $0.5^{\S}$ & $5-7$ \\
\hline
\end{tabular}

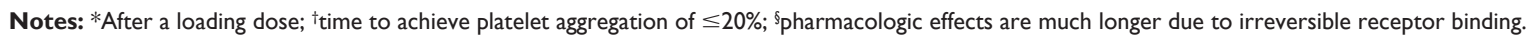

Abbreviation: IPA, inhibition of platelet aggregation.

daily compared with placebo and clopidogrel $75 \mathrm{mg}$ once daily. ${ }^{15}$ This study included patients with stable coronary artery disease who were receiving low-dose (75-100 mg per day) aspirin therapy. Patients were divided into one of three groups, ie, ticagrelor $(n=57)$, clopidogrel $(n=54)$, or placebo $(n=12)$. The ticagrelor and clopidogrel groups received loading doses (180 $\mathrm{mg}$ and $600 \mathrm{mg}$, respectively) before receiving the maintenance dosages. Fifty patients in each of the treatment arms were necessary for a $91 \%$ power to detect mean differences in IPA of $15 \%$ or more in the two treatment groups. Platelet function was determined by the use of three tests, ie, LTA, the VerifyNow P2 ${ }_{12}$ assay, and vasodilator-stimulated phosphoprotein-P. The primary outcome for onset was IPA $(20 \mu \mathrm{mol} / \mathrm{L}$ ADP $)$ at 2 hours post initial dose, and offset was assessed by the slope of the IPA between 4 and 72 hours after the final study dose. The primary outcome was much greater in the ticagrelor group compared with the clopidogrel group ( $88 \%$ versus $38 \%, P<0.0001$ ). There was no difference in IPA in the ticagrelor group at 2 hours and 8 hours post loading dose, while IPA was greater in the clopidogrel group at 8 hours compared with 2 hours post loading dose $(P=0.02)$. The maximum IPA was much higher in the ticagrelor group (93\%) when compared with the clopidogrel group (58\%) after the loading dose ( $P$ value not reported). The time to reach maximum IPA was faster in the ticagrelor group (2.0 hours) compared with the clopidogrel group ( 7.8 hours; $P$ value not reported). Ticagrelor also had a faster offset of antiplatelet action compared with clopidogrel. The primary outcome for offset was higher in the ticagrelor group than in the clopidogrel group $(P<0.0001)$.

A subanalysis of the ONSET/OFFSET data focused on the offset of antiplatelet action of both ticagrelor and clopidogrel with a high antiplatelet drug response. ${ }^{25}$ Platelet activity was evaluated in this study in a similar fashion to the other studies discussed in this section. All three tests, LTA, VerifyNow, and vasodilator-stimulated phosphoprotein-P, showed significant differences in platelet function for ticagrelor compared with clopidogrel at 48 hours after the last dose was given. The IPA at 48 hours for clopidogrel was approximately $60 \%$ compared with less than $40 \%$ for ticagrelor $(P<0.01)$. There was good recovery of platelet function by 72 hours in patients treated with ticagrelor, with IPAs of about $20 \%$ in patients with high platelet reactivity and about $10 \%$ in patients without high platelet reactivity. This is in comparison with values of about $45 \%$ and $20 \%$, respectively, for clopidogrel. The IPA for ticagrelor after 2 days (36\%) was similar to the IPA for clopidogrel after 5 days (33\%) from the last treatment dose. Since it is recommended that clopidogrel be withheld 5 days prior to surgery, ${ }^{26}$ these data can be useful for gauging how long a clinician should withhold ticagrelor before an invasive procedure. While the prescribing information for ticagrelor recommends discontinuation of ticagrelor 5 days prior to surgery, ${ }^{20}$ one can argue for a shorter window of about 3 days based on the ONSET/OFFSET data.

\section{Clinical trials}

The clinical trial program for ticagrelor is weighted heavily on two studies, ie, DISPERSE-2 ${ }^{27}$ and the PLATelet inhibition and patient Outcomes (PLATO) trial. ${ }^{28}$ Based on the original DISPERSE trial, which demonstrated good safety and tolerability and superior antiplatelet efficacy with $100 \mathrm{mg}$ and $200 \mathrm{mg}$ twice daily dosages of ticagrelor compared with clopidogrel, ${ }^{17}$ the multicenter DISPERSE-2 trial was performed to analyze the safety and efficacy of ticagrelor in 984 patients with non-ST elevation ACS. These patients were randomized in a double-blind fashion to receive ticagrelor $90 \mathrm{mg}$ twice daily $(\mathrm{n}=334)$, ticagrelor $180 \mathrm{mg}$ twice daily ( $\mathrm{n}=323$ ), or clopidogrel $75 \mathrm{mg}$ once daily following a $300 \mathrm{mg}$ loading dose $(\mathrm{n}=327)$ in addition to aspirin and other adjunctive therapies. It should be noted that the $90 \mathrm{mg}$ and $180 \mathrm{mg}$ doses of ticagrelor used in DISPERSE- 2 were reformulations of the $100 \mathrm{mg}$ and $200 \mathrm{mg}$ doses used in DISPERSE. The primary endpoint of major or minor bleeding at 4 weeks was seen with similar frequencies in each group ( $P=$ not statistically significant $[\mathrm{NS}]$ ): $8.1 \%$ (clopidogrel), $9.8 \%$ (ticagrelor $90 \mathrm{mg}$ ), and $8.0 \%$ (ticagrelor $180 \mathrm{mg}$ ). When major and minor bleeds were analyzed separately, the only statistically significant difference was that minor bleeds were seen more frequently with $180 \mathrm{mg}$ twice daily of ticagrelor compared with clopidogrel at 4 weeks $(1.3 \%$ 
versus $3.8 \% ; P=0.05)$ and at 12 weeks $(1.3 \%$ versus $6.1 \%$; $P=0.01)$. With regards to the secondary endpoint of major adverse cardiovascular events (myocardial infarction [MI], death, stroke, severe recurrent ischemia), a favorable trend was seen only with the ticagrelor $180 \mathrm{mg}$ group compared with clopidogrel in terms of fewer MIs at 4 weeks $(3.5 \%$ versus $1.0 \% ; P=0.047)$ and 12 weeks $(5.6 \%$ versus $2.5 \%$; $P=0.06)$. Nonhemorrhagic adverse events were comparable between the clopidogrel, $90 \mathrm{mg}$ ticagrelor, and $180 \mathrm{mg}$ ticagrelor groups except for dyspnea $(6.4 \%, 10.5 \%[P=0.07$ versus clopidogrel $]$ and $15.8 \%[P<0.0002$ versus clopidogrel], respectively), nausea $(3.4 \%, 6.6 \%$ and $6.5 \%$ [both $P=0.07$ versus clopidogrel $])$, diarrhea $(3.4 \%, 3.0 \%[P=\mathrm{NS}$ versus clopidogrel] and 7.4\% ( $P=0.02$ versus clopidogrel), hypotension $(0.6 \%, 4.2 \%[P=0.004$ versus clopidogrel $]$ and $3.7 \%[P=0.01$ versus clopidogrel $]$ ), and asymptomatic ventricular pauses $>2.5$ seconds $(4.3 \%, 5.5 \%[P=\mathrm{NS}$ versus clopidogrel $]$ and $9.9 \%[P=0.014$ versus clopidogrel $]$ ). A subgroup of patients $(\mathrm{n}=330)$ received a $270 \mathrm{mg}$ loading dose of ticagrelor prior to their maintenance dosage, but this was found to have no impact on the rate of the primary endpoint. In summary, DISPERSE-2 demonstrated $90 \mathrm{mg}$ ticagrelor twice daily to possess similar safety and efficacy compared with clopidogrel, and ticagrelor $180 \mathrm{mg}$ twice daily to have poorer safety compared with clopidogrel. Accordingly, the $90 \mathrm{mg}$ twice daily dose of ticagrelor was pursued further in clinical development with the PLATO trial.

The multicenter PLATO trial randomized 18,624 patients with ACS (symptom onset within 24 hours) to receive double-blind treatment with either ticagrelor $90 \mathrm{mg}$ twice daily following a $180 \mathrm{mg}$ loading dose $(\mathrm{n}=9333)$ or clopidogrel $75 \mathrm{mg}$ once daily following a $300-600 \mathrm{mg}$ loading dose $(\mathrm{n}=9291) \cdot{ }^{28}$ All patients also received aspirin $75-100 \mathrm{mg}$ daily (325 mg daily was permitted for 6 months after stent placement). The final diagnosis was ST elevation $\mathrm{MI}$ in $38 \%$ of patients, non-ST elevation MI in $43 \%$, and unstable angina in $17 \% ; 64 \%$ underwent percutaneous intervention during the study period and $10 \%$ underwent coronary artery bypass grafting $(\mathrm{CABG})$. The primary endpoint of vascular death, MI, or stroke at 12 months (median duration of treatment was 277 days) occurred in $9.8 \%$ of patients receiving ticagrelor and $11.7 \%$ of patients receiving clopidogrel (hazard ratio [HR] 0.84; 95\% confidence interval [CI] 0.77-0.92; $P<0.001)$. As individual endpoints, ticagrelor resulted in significant reductions in vascular death $(4.0 \%$ versus $5.1 \% ; P=0.001)$ and $\mathrm{MI}(5.8 \%$ versus $6.9 \% ; P=0.005)$, but not stroke ( 1.5 versus $1.3 \%$; $P=0.22)$. Total mortality $(4.5 \%$ versus $5.9 \% ; P<0.001)$ and stent thrombosis $(1.3 \%$ versus $1.9 \% ; P=0.009)$ were also lower with ticagrelor. Major bleeding rates were comparable between ticagrelor and clopidogrel (11.6\% versus $11.2 \%$; $P=0.43$ ), although combined major and minor bleeding was greater with ticagrelor $(16.1 \%$ versus $14.6 \% ; P=0.008)$, as was non-CABG-related major bleeding $(4.5 \%$ versus $3.8 \% ; P=0.03)$ and fatal intracranial bleeding $(0.1$ versus $0.01 \% ; P=0.02)$, although fatal nonintracranial bleeding was higher with clopidogrel $(0.3 \%$ versus $0.1 \% ; P=0.03)$. Despite the low event rates, intracranial bleeding is enough of a concern that prior intracranial hemorrhage is a contraindication to ticagrelor therapy. ${ }^{20}$ As with the DISPERSE-2 trial, dyspnea was the major nonhemorrhagic side effect of ticagrelor, occurring in $13.8 \%$ of patients ( $7.8 \%$ clopidogrel; $P<0.001)$ and leading to discontinuation of study treatment in $0.9 \%$ of patients $(0.1 \%$ clopidogrel; $P<0.001)$. While ventricular pauses of at least 3 seconds were more common with ticagrelor during the first week of treatment $(5.8 \%$ of patients versus $3.6 \%$ with clopidogrel; $P=0.01$ ), these had subsided by 30 days of treatment $(2.1 \%$ versus $1.7 \%$ clopidogrel; $P=0.52)$ and were rarely symptomatic. Increases in serum uric acid (15\% versus $7 \%$ ) and serum creatinine (11\% versus $9 \%$ ) at 12 months were also more common with ticagrelor compared with clopidogrel $(P<0.001$ for both).

Several subanalyses of the PLATO trial have been published, which corroborate the overall result of the parent trial. Specifically, patients with ST elevation MI intended for reperfusion with primary percutaneous coronary intervention $(\mathrm{n}=7544),{ }^{29}$ patients intended for noninvasive management of ACS $(\mathrm{n}=5216),{ }^{30}$ patients intended for invasive management of ACS $(n=13,408),{ }^{31}$ patients undergoing $\operatorname{CABG}(\mathrm{n}=1899),{ }^{32}$ patients with diabetes $(\mathrm{n}=4662),{ }^{33}$ and patients with chronic kidney disease (creatinine clearance $<60 \mathrm{~mL} / \mathrm{min} ; \mathrm{n}=3237$ ) ) $^{34}$ all demonstrated efficacy and safety with ticagrelor similar to that seen in the original PLATO trial.

Sixty-six different predefined subgroups were analyzed in PLATO, 33 looking at the primary efficacy endpoint (eight of which were defined post hoc rather than predefined) and 33 looking at major bleeding. With regards to efficacy, 30 of 33 subgroups showed ticagrelor to be more efficacious than clopidogrel; the three subgroups that showed no efficacy benefit with ticagrelor compared with clopidogrel were: patients enrolled in North American sites (HR 1.25, 95\% CI 0.93-1.67); males $<82 \mathrm{~kg}$ or females $<71 \mathrm{~kg}$ (HR 0.93 , 95\% CI 0.82-1.05); and patients not taking a lipid-lowering drug (HR 1.02, 95\% CI 0.83-1.24). ${ }^{28}$ For major bleeding, ticagrelor was similar to clopidogrel in all subgroups except 
those patients with a body mass index of $30 \mathrm{~kg} / \mathrm{m}^{2}$ or greater, who experienced more major bleeding with ticagrelor (HR $1.21,95 \%$ CI 1.02-1.45; $P=0.05$ ). Of particular concern was the North American subgroup, which not only demonstrated a lack of benefit from ticagrelor compared with clopidogrel, but actually suggested that perhaps clopidogrel was a more efficacious drug in this population. ${ }^{28}$ This finding initially led the United States Food and Drug Administration not to approve ticagrelor in the United States in 2010 pending further investigation of this geographic phenomenon. After several months of deliberation and data analysis by two independent statistical groups, it was concluded that the trial conduct was appropriate and that this phenomenon might have been a play of chance. ${ }^{35}$ However, of 37 different factors studied in effect modifier analyses, aspirin dosage stood out as the most likely explanation for the regional differences in treatment effect. Specifically, $53.6 \%$ of patients in the United States took a median daily aspirin dosage of at least $300 \mathrm{mg}$ compared with $1.7 \%$ in the rest of the world. In the United States, patients taking at least $300 \mathrm{mg}$ per day of aspirin, the HR for the primary efficacy endpoint was 1.62 (95\% CI 0.99-2.64), suggesting benefit with clopidogrel over ticagrelor. When lower daily dosages of aspirin were analyzed ( $\leq 100 \mathrm{mg}$ ), ticagrelor actually demonstrated a benefit in the United States population similar to that seen in the rest of the world (Figure 3). ${ }^{35}$ For this reason, the United States labeling for ticagrelor clearly states that maintenance dosages of aspirin should not exceed $100 \mathrm{mg}$ daily for patients taking ticagrelor. ${ }^{20}$

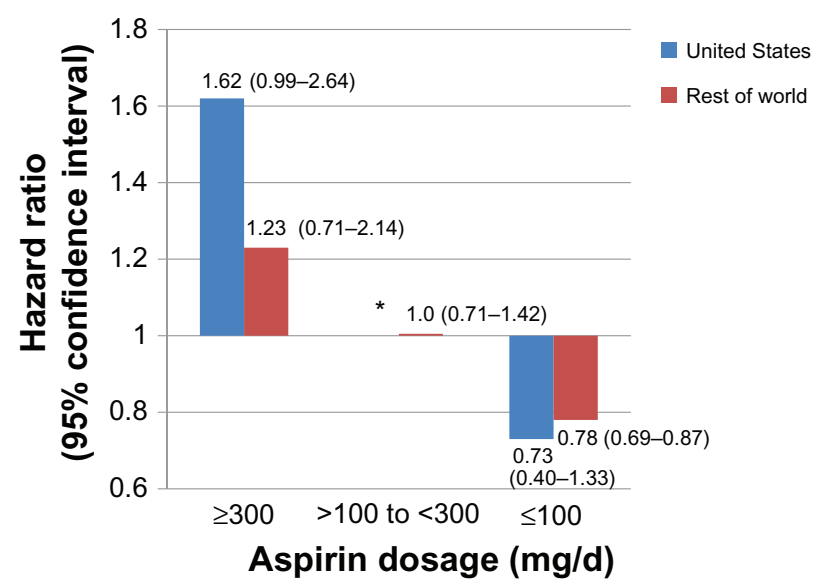

Figure 3 Hazard ratios and 95\% confidence intervals (in parentheses) for the PLATO study population with regards to the primary efficacy endpoint subdivided by daily aspirin dosage and geographic region. Daily dosages of aspirin $>300 \mathrm{mg}$ were associated with a blunting of the benefit of ticagrelor, whereas dosages $<100 \mathrm{mg}$ were associated with benefit of ticagrelor compared to clopidogrel. This finding was seen regardless of geographic region, but was most pronounced in the United States population which tended to use higher daily dosages of aspirin compared to the rest of the world. ${ }^{35}$

Note: *Insufficient data in the United States population.
The clinical trial program with ticagrelor continues with the ongoing PEGASUS-TIMI 54 trial being conducted by the Thrombolysis in Myocardial Infarction (TIMI) investigators. PEGASUS (Prevention of Cardiovascular Events in Patients with Prior Heart Attack Using Ticagrelor Compared with Placebo on a Background of Aspirin) is expected to enroll 21,000 post-MI patients with stable coronary artery disease from 30 countries, with $25 \%$ of subjects expected to be from the United States. The primary endpoint is cardiovascular death, nonfatal MI, or nonfatal stroke. The three treatments being studied are ticagrelor $90 \mathrm{mg}$ twice daily, ticagrelor $60 \mathrm{mg}$ twice daily, and placebo. This study is scheduled to be completed in February 2014. ${ }^{36}$

\section{Adverse effects}

As mentioned above, the PLATO study demonstrated, not unexpectedly, that bleeding was the most common adverse effect seen with ticagrelor therapy, with major or minor bleeds occurring in $16.1 \%$ of patients (versus $14.6 \%$ with clopidogrel; $P=0.008) .{ }^{28}$ However, ticagrelor also has several off-target adverse effects (Table 2), arguably one of the more concerning being dyspnea. The DISPERSE-2 trial demonstrated a dose-response relationship with ticagrelor and dyspnea, with a $10.5 \%$ incidence of this adverse effect with ticagrelor $90 \mathrm{mg}$ twice daily and a $15.8 \%$ incidence with $180 \mathrm{mg}$ twice daily (versus $6.4 \%$ with clopidogrel). ${ }^{27} \mathrm{~A}$ subgroup analysis of the ONSET/OFFSET trial assessed cardiopulmonary function in 123 patients receiving ticagrelor $90 \mathrm{mg}$ twice daily, clopidogrel $75 \mathrm{mg}$ once daily, or placebo. ${ }^{37}$ The investigators were mainly interested in dyspnea, defined as shortness of breath either during exercise or at rest and was graded as mild, moderate, or severe. Cardiopulmonary evaluations were evaluated at baseline and at the end of 6 weeks of treatment or sooner if dyspnea or other adverse events were recorded. Dyspnea occurred in 38.6\%, 9.3\%, and $8.3 \%$ of patients in the ticagrelor group, clopidogrel group, and placebo group, respectively (ticagrelor versus clopidogrel, $P<0.001$; ticagrelor versus placebo, $P<0.05$; clopidogrel versus placebo, not statistically significant). Most of the cases of dyspnea were considered mild in nature with only three cases in the ticagrelor group deemed to be of moderate severity. Three patients stopped taking the study treatment (all were taking ticagrelor) due to dyspnea; two were categorized as moderate dyspnea and one as mild. No cases of dyspnea were deemed to be severe. In the ticagrelor group, 17 of the 22 patients who experienced dyspnea had this occur within the first week of starting medication. While many cases of dyspnea with ticagrelor lasted less 
Table 2 Nonhemorrhagic side effects observed with ticagrelor in PLATO 20,28

\begin{tabular}{lll}
\hline & $\begin{array}{l}\text { Ticagrelor } \\
(\mathbf{n}=\mathbf{9 2 3 5})\end{array}$ & $\begin{array}{l}\text { Clopidogrel } \\
(\mathbf{n}=\mathbf{9 1} \mathbf{8 6})\end{array}$ \\
\hline Dyspnea & $13.8 \%$ & $7.8 \%$ \\
Headache & $6.5 \%$ & $5.8 \%$ \\
Cough & $4.9 \%$ & $4.6 \%$ \\
Dizziness & $4.5 \%$ & $3.9 \%$ \\
Nausea & $4.3 \%$ & $3.8 \%$ \\
Atrial fibrillation & $4.2 \%$ & $4.6 \%$ \\
Hypertension & $3.8 \%$ & $4.0 \%$ \\
Non-cardiac chest pain & $3.7 \%$ & $3.3 \%$ \\
Diarrhea & $3.7 \%$ & $3.3 \%$ \\
Back pain & $3.6 \%$ & $3.3 \%$ \\
Hypotension & $3.2 \%$ & $3.3 \%$ \\
Fatigue & $3.2 \%$ & $3.2 \%$ \\
Chest pain & $3.1 \%$ & $3.5 \%$ \\
Gynecomastia & $0.23 \%$ & $0.05 \%$ \\
Increase in serum & $7.4 \%$ & $5.9 \%$ \\
creatinine $>50 \%$ & & \\
Increase in serum uric acid & $0.6 \mathrm{mg} / \mathrm{dL}$ & $0.2 \mathrm{mg} / \mathrm{dL}$ \\
from baseline & & \\
\hline Note & & \\
\hline
\end{tabular}

Note: Numbers are represented as percentage of patients unless stated otherwise. Abbreviation: PLATO, PLATelet inhibition and patient Outcomes.

than 24 hours, several patients experienced dyspnea over the duration of the study. Most cases of dyspnea resolved following drug discontinuation. Electrocardiography, echocardiography, and pulmonary function tests were also performed at baseline and after 6 weeks of treatment, none of which were significantly affected by ticagrelor.

Dyspnea and pulmonary function were also extensively analyzed in the PLATO trial, which demonstrated dyspnea rates of $13.8 \%$ with ticagrelor (versus $7.8 \%$ with clopidogrel; $P<0.001)$ and resulted in discontinuation of study treatment in $0.9 \%$ of patients (versus $0.1 \%$ clopidogrel; $P<0.001$ ). ${ }^{28}$ Overall, $14.5 \%$ of patients randomized to ticagrelor reported dyspnea at any point during the study (both on and off study treatment) compared with $8.7 \%$ of patients taking clopidogrel $(P<0.001) .{ }^{38}$ Of these cases, only $0.4 \%$ (ticagrelor) and $0.3 \%$ (clopidogrel) were deemed by the study investigator to be of severe intensity. The median onset of dyspnea symptoms was 23 days from the onset of therapy with ticagrelor versus 43 days with clopidogrel $(P<0.0001)$. The majority of cases of dyspnea resolved either spontaneously or upon discontinuation of medication. The overall efficacy and safety of ticagrelor with respect to major adverse cardiovascular events and bleeding did not appear to be affected by the presence of dyspnea. ${ }^{38}$ Pulmonary function studies were also performed in 199 patients in PLATO (101 patients receiving ticagrelor, 98 patients receiving clopidogrel), with no significant changes in pulmonary function demonstrated with ticagrelor administration in this subgroup. ${ }^{39}$ While the mechanism for ticagrelor-induced dyspnea had not been clearly elucidated, a popular hypothesis is that ticagrelor inhibits adenosine reuptake and thereby increases extracellular adenosine concentrations, and exogenous adenosine administration is known to cause dyspnea, perhaps through activation of $\mathrm{A}_{1}$ receptors and resulting stimulation of pulmonary vagal $\mathrm{C}$ fibers. ${ }^{38-40}$

Another concerning adverse effect with ticagrelor in clinical trials was a dose-related increase in the incidence of ventricular pauses. This was initially seen in the DISPERSE-2 trial and was one factor in the abandonment of the $180 \mathrm{mg}$ dosage of ticagrelor in late-phase clinical development. ${ }^{27}$ A subgroup of 2908 patients in the PLATO trial underwent continuous ECG monitoring to document the frequency of ventricular pauses and clinical bradycardic events in patients taking ticagrelor $(n=1472)$ or clopidogrel $(n=1436) .{ }^{41}$ Ventricular pauses lasting at least 3 seconds occurred more frequently with ticagrelor (5.8\%) compared with clopidogrel (3.6\%; $P=0.006)$ during the first week of therapy, but this difference was not significant after 30 days of treatment $(2.1 \%$ versus $1.7 \%$ for ticagrelor and clopidogrel, respectively, $P=0.52$ ). These pauses were largely asymptomatic, transient, nocturnal, and emanated from the sinus node. The incidence of clinically reported bradycardic adverse events did not differ between ticagrelor and clopidogrel through 12 months of follow-up. As with ticagrelor-induced dyspnea, the mechanism(s) responsible for ventricular pauses with ticagrelor remain to be elucidated but may involve inhibition of adenosine reuptake by erythrocytes with resulting increases in adenosine concentrations at the sinoatrial and atrioventicular nodes. ${ }^{41}$

In the PLATO trial, elevations in serum creatinine and uric acid were seen more frequently in patients taking ticagrelor compared with clopidogrel (Table 2). ${ }^{28}$ Concentrations of these compounds returned to baseline following drug discontinuation. The mechanism(s) for this is unknown, but may be related to impaired purine catabolism due to increased adenosine concentrations. ${ }^{42}$ These side effects have not been attributed to either prasugrel or clopidogrel.

\section{Drug interactions}

As mentioned earlier, ticagrelor has the advantage over the thienopyridines of not requiring metabolic activation for activity. This would theoretically reduce the potential for drug-drug interactions with ticagrelor. Both CYP3A4 and, to a lesser extent, CYP3A5 have been identified as the isozymes responsible for the formation of the active and inactive metabolites of ticagrelor. ${ }^{19}$ As such, strong inhibitors (ie, ketoconazole, itraconazole, clarithromycin, 
nefazodone, ritonavir, saquinavir, nelfinavir, indinavir, atazanavir, telithromycin) or inducers (ie, rifampin, dexamethasone, phenytoin, carbamazepine, phenobarbital) of these enzymes may interfere with the activity of ticagrelor, and concomitant administration should be avoided. ${ }^{20}$ Ticagrelor is also an inhibitor of CYP3A4 and CYP3A5 and may increase serum concentrations of simvastatin and lovastatin which rely on CYP3A4 for metabolism. The daily dosages of simvastatin and lovastatin should not exceed $40 \mathrm{mg}$ when given in combination with ticagrelor. ${ }^{20}$ Ticagrelor is an inhibitor of the P-glycoprotein transporter and may therefore increase serum digoxin concentrations; these should be monitored with initiation or change in ticagrelor therapy. ${ }^{20}$ As mentioned above, aspirin dosage should not exceed $100 \mathrm{mg}$ per day when given with ticagrelor due to a potential loss in ticagrelor efficacy. Ticagrelor can be safely administered with unfractionated or low-molecular-weight heparin, glycoprotein IIb/IIIa inhibitors, beta-blockers, angiotensin-converting enzyme inhibitors, angiotensin receptor antagonists, and proton pump inhibitors. ${ }^{20}$ Proton pump inhibitors have mechanistically been shown to inhibit CYP2C19, which may interfere with the activation of clopidogrel. However, it is debatable as to whether or not giving clopidogrel in combination with a proton pump inhibitor is detrimental in terms of clinical outcomes. ${ }^{43,44}$ Because CYP2C19 is not a major metabolic pathway for ticagrelor metabolism, a potential pharmacokinetic interaction with proton pump inhibitors is not concerning.

\section{Other practical considerations with ticagrelor therapy}

The major efficacy and safety issues involving ticagrelor therapy have been discussed up to this point, but much more needs to be considered when deciding on how to integrate ticagrelor into clinical practice. Some of these issues are discussed below and summarized in Table 3.

\section{Aspirin dosage}

The prescribing information for ticagrelor contains a boxed warning regarding a potential loss of efficacy with ticagrelor when given concomitantly with daily aspirin dosages exceeding $100 \mathrm{mg}$ per day. ${ }^{20}$ The genesis of this warning is discussed earlier in this article, and clinicians and patients need to be aware of this and prescribe and consume aspirin in accordance with this warning. While a biological explanation has not been clearly defined to explain why higher dosages of aspirin may blunt the effectiveness of ticagrelor, it has been hypothesized that some of the benefits of ticagrelor may be dependent on prostacyclin, the production of which may be blocked by daily doses of aspirin exceeding $80 \mathrm{mg} .{ }^{45}$ The reliance on prostacyclin for an antiplatelet effect may relate directly to the degree of $\mathrm{P} 2 \mathrm{Y}_{12}$ inhibition, which would explain why the more potent ticagrelor would be more susceptible to an aspirin interaction than clopidogrel. ${ }^{45}$ In the absence of a clear explanation for an aspirin-ticagrelor interaction, some experts are reluctant to accept that such an interaction even exists. ${ }^{46}$ Even though the European countries in PLATO all used the same low daily dosage of aspirin, there were differences in outcomes among those countries, with some results favoring clopidogrel, some favoring ticagrelor, and some neutral, arguing that aspirin dosage did not impact the study results. ${ }^{46}$

Others have looked at the issue of an interaction between aspirin and ticagrelor from a different perspective, namely questioning whether or not aspirin is even needed when ticagrelor is being administered. This is a difficult question

Table 3 Practical considerations when comparing clopidogrel, prasugrel, and ticagrelor

\begin{tabular}{llll}
\hline & Clopidogrel & Prasugrel & Ticagrelor \\
\hline Indication(s) & $\begin{array}{l}\text { ACS; recent Ml, stroke, or } \\
\text { established peripheral }\end{array}$ & ACS with PCl & ACS \\
& $\begin{array}{l}\text { arterial disease } \\
\text { Once daily }\end{array}$ & Once daily & Twice daily \\
Dosing frequency & $75-325 \mathrm{mg} /$ day & $75-325 \mathrm{mg} /$ day & $\leq 100 \mathrm{mg} /$ day \\
Concomitant aspirin dosage & Yes & No & No \\
Pharmacogenomic variability in antiplatelet effect? & None & Prior transient ischemic & Prior intracranial hemorrhage, \\
Contraindications other than active bleeding & & attack or stroke & severe hepatic impairment \\
or drug hypersensitivity & Possible & No & No \\
Interaction with proton pump inhibitors? & $\$ 222.55$ & $\$ 222.16$ & $\$ 265.13$ \\
AWP cost/30 days* & $\$ 174.76$ & $\$ 174.45$ & N/A \\
UNMH cost/30 days* &
\end{tabular}

Note: *Prices are expressed as United States dollars.

Abbreviations: ACS, acute coronary syndrome; AWP, average wholesale price; MI, myocardial infarction; N/A, not available; PCl, percutaneous coronary intervention; UNMH, University of New Mexico Hospital. 
to answer because aspirin is the standard of care for treatment and prevention of atherothrombotic disease and the thienopyridines and ticagrelor are added to, rather than given in place of, aspirin in clinical trials for ethical reasons. From a pharmacologic perspective, potent $\mathrm{P} 2 \mathrm{Y}_{12}$ receptor blockade leads to a reduction in the ability of platelets to produce thromboxane $\mathrm{A} 2$, the primary target for the antiplatelet effect of aspirin. ${ }^{45,47}$ Accordingly, it has been questioned whether or not aspirin is having much, if any, antiplatelet effect in this setting because the potent $\mathrm{P} 2 \mathrm{Y}_{12}$ antagonists are essentially serving an aspirin-like function in suppressing thromboxane A2 production. In this scenario, aspirin may paradoxically be detrimental, because it may then function primarily to suppress production of beneficial prostanoids such as prostaglandin $\mathrm{I}_{2}{ }^{45}$ While prostanoid inhibition is also seen with aspirin monotherapy, the beneficial antiplatelet effect may outweigh any detrimental effects on prostanoid production, resulting in a net clinical benefit. ${ }^{45}$ The determination of how much incremental benefit aspirin adds to thienopyridine or ticagrelor therapy needs to be investigated in clinical trials before any conclusions can be made in this regard. For now, published clinical studies support the combination of a $\mathrm{P} 2 \mathrm{Y}_{12}$ receptor antagonist with aspirin and clinical practice should reflect this.

\section{Efficacy in clopidogrel nonresponders}

It has been fairly well established that there is interpatient variability in the antiplatelet effects of clopidogrel, which is largely believed to be due to genetic polymorphisms of the CYP2C19 enzyme responsible for converting clopidogrel to its active form. ${ }^{48,49}$ It has been documented that the frequencies of poor metabolizers of CYP2C19 are 2\% in White, $4 \%$ in Black, and $14 \%$ in Chinese racial groups. ${ }^{26}$ The two polymorphisms that account for nonfunctional CYP2C19 enzymes are CYP2C19*2 and *3 which are seen in $85 \%$ of White and $99 \%$ of Asian poor metabolizers. ${ }^{26}$ Major adverse cardiovascular events have been shown to occur more often in patients with reduced CYP2C19 function taking clopidogrel compared with those having good CYP2C19 function. ${ }^{50}$ Genetic testing for CYP2C19 polymorphisms is now commercially available and is beginning to gain traction as a means of screening patients to predict the antiplatelet efficacy of clopidogrel. Patients who have a diminished antiplatelet effect in response to clopidogrel are deemed "nonresponders" or "poor responders", and a proven alternative antiplatelet therapy for these patients would be very desirable.

The Response to Ticagrelor in Clopidogrel Nonresponders and Responders and Effect of Switching Therapies
(RESPOND) study was designed to investigate the antiplatelet effect of ticagrelor in clopidogrel nonresponders. ${ }^{51}$ Clopidogrel response was judged in 98 patients with stable coronary artery disease based on ADP-induced platelet aggregation following administration of a $300 \mathrm{mg}$ loading dose of clopidogrel. Inhibition of platelet aggregation using LTA of $>10 \%$ defined clopidogrel response and $\leq 10 \%$ clopidogrel nonresponse. After being categorized as a clopidogrel responder $(n=57)$ or nonresponder $(n=41)$, patients were randomly assigned to receive one of two double-blind treatments, ie, a $600 \mathrm{mg}$ clopidogrel load followed by $75 \mathrm{mg}$ once daily for $14 \pm 2$ days or a $180 \mathrm{mg}$ ticagrelor load followed by $90 \mathrm{mg}$ twice daily for $14 \pm 2$ days. After this initial study phase, all of the nonresponders switched study treatments, while only half of the responders switched treatments (the other half remained on the same treatment), which were also given for $14 \pm 2$ days. All patients also received aspirin 75-100 mg once daily. Of the patients initially identified as nonresponders to clopidogrel, 100\% responded to ticagrelor after 2 weeks of treatment, defined as a $>10 \%$ decrease in platelet aggregation from baseline. This is in comparison with a $75 \%$ response rate for clopidogrel $(P=0.005)$. Decreases in platelet aggregation of $>30 \%$ and $>50 \%$ were seen in $75 \%$ and $13 \%$ of ticagrelor patients, respectively, compared with $13 \%(P<0.001)$ and $0 \%(P=0.046)$ of patients receiving clopidogrel. Mean platelet aggregation increased from $36 \%$ to $56 \%(P<0.0001)$ in the patients who crossed over to receive clopidogrel (initially on ticagrelor) in the second phase of the study, whereas those patients who were initially on clopidogrel and crossed over to receive ticagrelor demonstrated a decrease in mean platelet aggregation from $59 \%$ to $35 \%(P<0.0001)$. In patients initially identified as clopidogrel responders, ticagrelor consistently demonstrated greater inhibition of platelet aggregation both before and after treatment crossover. These results not only demonstrated that ticagrelor was superior to clopidogrel in terms of inhibiting platelet aggregation both in clopidogrel responders and nonresponders, but also that ticagrelor is effective in patients who do not demonstrate an antiplatelet effect in response to clopidogrel, producing inhibition of platelet aggregation in these patients that is comparable with that seen in clopidogrel responders.

Genetic substudies were performed in the RESPOND, ONSET/OFFSET, and PLATO trials in an attempt to determine the effect of CYP2C19 metabolizer status on the efficacy of ticagrelor and clopidogrel.52,53 The combined data from RESPOND and ONSET/OFFSET demonstrated the antiplatelet effects of clopidogrel to be dependent on the 
CYP2C19 genotype, with loss-of-function carriers (ie, poor metabolizers) and intermediate metabolizers having a higher degree of platelet function. No such relationship was seen with ticagrelor. ${ }^{52}$ In the PLATO genetic substudy, patients with a loss-of-function CYP2C19 allele receiving clopidogrel had a higher incidence of the primary endpoint of major adverse cardiovascular events compared with patients receiving clopidogrel who did not have any loss-of-function alleles. The event rate with ticagrelor was similar regardless of CYP2C19 polymorphisms. ${ }^{53}$

Together, these studies demonstrate ticagrelor to have comparable efficacy regardless of CYP2C19 metabolizer status, unlike clopidogrel, and to be a viable alternative to clopidogrel in those patients deemed to be nonresponders to clopidogrel.

\section{Economics}

As with many new medications, drug cost promises to be a critical factor in determining the current place in therapy for ticagrelor, particularly with the pending generic availability of clopidogrel (expected May 2012 in the United States). While the acquisition cost of ticagrelor will in all probability be higher than generic clopidogrel, economic factors other than drug cost itself need to be considered when deciding on the status of clopidogrel by institutional and health plan formularies. Cost effectiveness data would represent one of these factors, and data with ticagrelor have just recently started to emerge in this regard.

An unpublished health economics substudy (available in abstract form only) from PLATO compared qualityadjusted like years (QALY) for ticagrelor and clopidogrel. ${ }^{54}$ Based on PLATO event rates and drug costs of $€ 0.17$ (\$0.23 United States dollars [USD]) per day for generic clopidogrel and $€ 2.25$ (\$3.00) to $€ 3.50$ (\$4.65) per day for ticagrelor, health care costs (based on Swedish base-case analysis) and QALYs were estimated. The results showed that patients receiving ticagrelor would be expected to gain an additional 0.13 QALYs at a cost of $€ 2350$ (\$3110) to $€ 5700$ (\$7550) per QALY compared with clopidogrel. This would indicate ticagrelor to be cost effective compared with clopidogrel since a threshold of $€ 38,000(\$ 50,000)$ per QALY is typically used to determine cost effectiveness in the United States. Another cost effectiveness analysis focused on comparing ticagrelor with genotype-driven therapy with clopidogrel in a cohort of Medicare patients with ACS. ${ }^{55}$ That study demonstrated an incremental cost effectiveness ratio of $\$ 10,059$ USD per QALY with ticagrelor therapy compared with genotype-driven clopidogrel therapy over a 5-year period.
Even in a simulation in which clopidogrel was \$4 USD per month, the cost effectiveness ratio would be \$11,927 USD per QALY with ticagrelor. It is estimated that ticagrelor would remain cost effective compared with genotype-driven clopidogrel therapy as long as the monthly cost of ticagrelor did not exceed \$693 USD per month. The average wholesale price at the time of writing for one month of ticagrelor therapy is \$265 USD (Table 3).

\section{Medication adherence}

As mentioned above, ticagrelor not only has a rapid onset in terms of antiplatelet activity, but it also has a faster offset than the thienopyridines. This may be beneficial, as mentioned earlier, in potentially decreasing the waiting time to surgery, especially if a patient needs CABG. However, there is also some concern that the relatively fast offset of antiplatelet effect may make medication adherence that much more important with ticagrelor. It has been shown that the antiplatelet effects of ticagrelor drop more precipitously than clopidogrel between 8 and 24 hours post-dose, although the IPA with ticagrelor seems to be maintained at a level comparable to or greater than clopidogrel over this time period. However, by 48 hours post dose, the IPA with ticagrelor is less than that seen with clopidogrel; by 72 hours post dose, the IPA with ticagrelor is about $20 \%$, which is comparable with that seen 5-7 days after discontinuation of clopidogrel. ${ }^{15,25}$ While there are no studies that have looked at clinical outcomes related to the offset of action of ticagrelor, measures should be taken to ensure that patients will be adherent with ticagrelor, and/or support needs to be given to those patients who have a history of poor adherence to other drugs. This is of added concern because ticagrelor needs to be taken twice daily, and medication adherence is inversely related to the number of daily doses. ${ }^{56}$ Patients need to be aware of the importance of not missing a dose and have a plan of action in case circumstances arise which would jeopardize adherence; for example, carrying extra tablets with them on trips in the event of an airplane flight cancellation which would extend their time away from home.

\section{Clinical comparison versus prasugrel}

There are no head-to-head comparisons with ticagrelor and prasugrel in terms of clinical outcomes. Prasugrel is a thienopyridine prodrug so, like clopidogrel requires bioactivation in order to produce a pharmacologic effect. Unlike clopidogrel, the bioactivation of prasugrel requires only one step instead of two. This drug is initially hydrolyzed in 
the intestines by esterases and converted to the active form primarily by CYP3A4 and CYP2B $6 .{ }^{57}$ The time to maximal IPA is slightly faster than clopidogrel with a loading dose, and prasugrel does have a higher maximal IPA compared with clopidogrel. ${ }^{58}$ The typical loading dose of prasugrel is $60 \mathrm{mg}$, which will lead to a maximal IPA of about $80 \%$ in approximately 2-4 hours (Table 1). ${ }^{57} \mathrm{~A}$ head-to-head comparison of ticagrelor and prasugrel demonstrated more potent inhibition of platelet aggregation with ticagrelor. ${ }^{47}$

Because prasugrel has the same mechanism of action as clopidogrel, it irreversibly inhibits platelets and needs approximately 7 days for the antiplatelet effects to wear off completely, given that new platelets will need to be synthesized. While more efficacious than clopidogrel, clinical trials have shown an increase in life-threatening, major, and fatal bleeds with prasugrel compared with clopidogrel. ${ }^{8}$ The bleeding risk was higher in specific subgroups of patients, including those who were 75 years of age or older, those who weighed less than 60 kilograms, and those who had a history of stroke or transient ischemic attacks. ${ }^{8}$ Prasugrel also showed no efficacy advantage over clopidogrel in terms of reducing major adverse cardiovascular events in these subgroups of patients. Restrictions have therefore been placed on prasugrel, and this drug carries a boxed warning because of the bleeding risks. Prasugrel should not be used in patients with a history of stroke or TIA. Extreme caution should be used in patients who are at least 75 years of age or weigh less than 60 kilograms. ${ }^{57} \mathrm{~A}$ meta-analysis indirectly comparing bleeding with ticagrelor and prasugrel was in favor of less bleeding with ticagrelor. ${ }^{59}$ While bleeding rates were higher with prasugrel than clopidogrel in TRITON-TIMI $38^{8}$ and comparable between ticagrelor and clopidogrel in PLATO,${ }^{28}$ when one compares bleeding rates according to the standardized TIMI criteria, one finds that, on a percentageby-percentage basis, a higher percentage of patients taking ticagrelor in PLATO experienced non-CABG-related major bleeding as well as major or minor bleeding, both defined by TIMI criteria, compared with patients taking prasugrel in
TRITON-TIMI 38 (Table 4). However, a greater percentage of patients taking prasugrel in TRITON-TIMI 38 reported major CABG-related bleeding compared with patients taking ticagrelor in PLATO. Bleeding rates with clopidogrel were higher in the PLATO trial compared with TRITONTIMI 38, even though both studies used similar clopidogrel doses, with the exception that $20 \%$ of patients in PLATO received a $600 \mathrm{mg}$ loading dose of clopidogrel instead of the standard $300 \mathrm{mg}$ loading dose (Table 4). Another difference is that the PLATO trial enrolled patients even if they had received clopidogrel before randomization, while patients in the TRITON-TIMI 38 study had to have discontinued clopidogrel for at least 5 days before randomization. It is unknown whether or not these differences in clopidogrel treatment contributed in any way to the higher bleeding rates with clopidogrel in PLATO versus TRITON-TIMI 38, thereby narrowing the window of difference between ticagrelor and clopidogrel in terms of bleeding rates, but these cannot be dismissed as contributing factors. It is also noteworthy that the major safety endpoint in PLATO was study-defined major bleeding, and it was non-CABG-related major TIMI bleeding in TRITON TIMI 38. This is not to say that prasugrel and ticagrelor are comparable in any way with regards to bleeding, because this was an indirect comparison and absolute numbers of bleeds were substantially lower in the TRITONTIMI 38 trial by virtue of an overall smaller sample size in relation to the PLATO study. However, it does argue for a standardized definition of bleeding in clinical trials in order to facilitate indirect comparisons such as these for which no direct head-to-head data exist. ${ }^{60}$

Both prasugrel and ticagrelor have shown superiority in efficacy over clopidogrel in patients with ACS. ${ }^{8,28}$ However, since these two new antiplatelet agents do not have any direct head-to-head comparison trials, the choice of which one to use in lieu of clopidogrel is not clear. An indirect comparative meta-analysis has been published to attempt to clarify this issue. ${ }^{59}$ This meta-analysis compared these two new antiplatelet agents indirectly through their

Table 4 Bleeding rates in the PLATO and TRITON-TIMI 38 trials based on TIMI criteria ${ }^{8,28}$

\begin{tabular}{|c|c|c|c|c|c|c|}
\hline & \multicolumn{3}{|l|}{ PLATO } & \multicolumn{3}{|c|}{ TRITON-TIMI 38} \\
\hline & Ticagrelor & Clopidogrel & $P$ value & Prasugrel & Clopidogrel & $P$ value \\
\hline CABG-related major bleeding* & 5.3 & 5.8 & 0.32 & 13.4 & 3.2 & $<0.001$ \\
\hline Non-CABG-related major bleeding* & 2.8 & 2.2 & 0.03 & $2.4^{\dagger}$ & $1.8^{+}$ & 0.03 \\
\hline Major or minor bleeding* & $\mathrm{II} .4$ & 10.9 & 0.33 & 5.0 & 3.8 & 0.002 \\
\hline Major bleeding, study criteria & $11.6^{\dagger}$ & $11.2^{\dagger}$ & 0.43 & NA & NA & NA \\
\hline
\end{tabular}

Notes: *According to TIMI criteria; ${ }^{\dagger}$ primary safety endpoint; numbers are expressed as percentage of patients.

Abbreviations: NA, not applicable; PLATO, PLATelet inhibition and patient Outcomes; TIMI, Thrombolysis in Myocardial Infarction. 
landmark trials, ie, PLATO for ticagrelor and TRITONTIMI 38 for prasugrel, and demonstrated no difference between these two drugs in terms of overall risk of death, nonfatal myocardial infarction, nonfatal stroke, or in their other composite endpoints. The only difference between the two drugs in terms of efficacy was that prasugrel was shown to have a significantly lower risk of definite or probable stent thrombosis (odds ratio $=0.64 ; 95 \% \mathrm{CI}$ $0.43-0.93 ; P=0.020)$. The cost of this benefit was an increased risk of any major TIMI bleeding, major bleeding associated with cardiac surgery, and major or minor TIMI bleeding with prasugrel. ${ }^{59}$ There have been conflicting views in terms of the differences between ticagrelor and prasugrel when the clinical efficacy of these drugs is indirectly compared. ${ }^{42}$ Looking more closely at these two trials in terms of mortality, ticagrelor reduced mortality in PLATO $(\mathrm{HR}=0.78 ; 95 \%$ CI $0.69-0.89 ; P<0.001)$ whereas prasugrel did not in TRITON-TIMI 38 (HR 0.95; 95\% CI 0.78-1.16; $P=0.64)$. The PLATO trial allowed patients into the trial if they had received clopidogrel before randomization while patients in the TRITON-TIMI 38 study had to be off clopidogrel for at least 5 days before randomization. This helps illustrate that the PLATO trial gives a more realistic view of what to expect when treating with these antiplatelet agents.

In terms of off-target adverse effects, ticagrelor may cause dyspnea and cardiac conduction abnormalities as mentioned above, which is not much of a concern with prasugrel therapy. Based on the premise that these side effects are due to ticagrelor-induced elevations in adenosine concentrations, one would not expect these side effects to occur with prasugrel. ${ }^{38,41}$ Additionally, ticagrelor may elevate serum creatinine and uric acid concentrations, which is not something that has been attributed to prasugrel. However, there is concern regarding cancer risk with prasugrel. Specifically, a $27 \%$ increased risk in colorectal, lung, and breast malignancies was seen in the TRITON-TIMI 38 trial with prasugrel compared with clopidogrel, primarily in women. ${ }^{42,61}$ However, this may very well be a chance finding, given that the absolute numbers of cases was low. In the PLATO study, the incidence of either any neoplasm or a malignant neoplasm arising during treatment was comparable between ticagrelor and clopidogrel, while the incidence of a benign neoplasm occurring was actually less with ticagrelor (0.2\%) compared with clopidogrel $(0.4 \% ; P=0.02){ }^{28}$

The potential efficacy of ticagrelor in clopidogrel nonresponders was discussed earlier, indicating that ticagrelor seems to be effective in these patients. ${ }^{52,53}$ Prasugrel has also been studied in patients with functional variants in clopidogrel-metabolizing enzymes and has shown potential in these patients as well. ${ }^{62,63}$ Because no head-to-head trials exist comparing ticagrelor with prasugrel in clopidogrel nonresponders, no conclusions can be made at this time regarding which agent to choose in this setting. Nonetheless, both prasugrel and ticagrelor have promise as alternative antiplatelet drugs for patients not responding adequately to clopidogrel.

\section{Summary}

Ticagrelor is the first reversible $\mathrm{P}_{2} \mathrm{Y}_{12}$ receptor antagonist to be available for clinical use. Compared with clopidogrel, ticagrelor elicits a faster and stronger antiplatelet effect and also displays greater clinical efficacy with a comparable rate of bleeding. Ticagrelor is indicated to be used with aspirin therapy, but only at aspirin dosages not exceeding $100 \mathrm{mg}$ daily, because the clinical data suggest that ticagrelor may lose efficacy when combined with higher dosages of aspirin, although this is a topic of debate. The relatively fast offset of effect of ticagrelor is desirable in the sense that invasive procedures will not need to be delayed as long for fear of bleeding. However, the quicker offset of effect makes medication adherence that much more important, because missing consecutive doses may increase the risk for thrombotic events. This is even more concerning given that ticagrelor is administered twice daily, making adherence more challenging compared with medications that are administered once daily (eg, clopidogrel, prasugrel). Bleeding is the most common side effect with ticagrelor, although dyspnea, ventricular pauses, and elevations in serum creatinine and uric acid are also associated with ticagrelor therapy. Ticagrelor has been shown to inhibit platelet aggregation effectively in patients nonresponsive to clopidogrel, and there are currently no known pharmacogenetic issues with ticagrelor. Ticagrelor is currently competitively priced against clopidogrel and prasugrel, although with clopidogrel becoming available as a generic very soon, drug costs will likely be a consideration when delineating the role of ticagrelor in the treatment of coronary artery disease. Direct comparisons with prasugrel are unfortunately lacking, and the relative merits of ticagrelor and prasugrel will have to be made based on indirect comparisons. Ticagrelor is a very promising new antiplatelet drug with impressive efficacy and reasonable safety. While ticagrelor has currently established itself for the treatment of acute coronary syndromes, ongoing and future trials in broader clinical scenarios will hopefully establish more clearly its ultimate place in therapy. 


\section{Disclosure}

The authors report no conflicts of interest in this work.

\section{References}

1. Dib C, Hanna E, Abu-Fadel M. A new era for antiplatelet therapy in patients with acute coronary syndrome. Am J Med Sci. 2010;340: 407-411.

2. Marczewski MM, Postula M, Dariusz K. Novel antiplatelet agents in the prevention of cardiovascular complications - focus on ticagrelor. Vasc Health Risk Manag. 2010;6:419-429.

3. Antiplatelet Trialists' Collaboration. Collaborative overview of randomized trials of antiplatelet therapy-I: prevention of death, myocardial infarction, and stroke by prolonged antiplatelet therapy in various categories of patients. BMJ. 1994;308:81-106.

4. Kushner FG, Hand M, Smith SC, et al. 2009 focused updates: ACC/ AHA Guidelines for the Management of Patients With ST-Elevation Myocardial Infarction. J Am Coll Cardiol. 2009;54:2205-2241.

5. Wright RS, Anderson JL, Adams CD, et al. 2011 ACCF/AHA focused update of the guidelines for the management of patients with unstable angina/non ST-elevation myocardial infarction. J Am Coll Cardiol. 2011;57:1920-1959

6. The Clopidogrel In Unstable Angina To Prevent Recurrent Events Trial Investigators. Effects of clopidogrel in addition to aspirin in patients with acute coronary syndromes without ST-segment elevation. $N$ Engl J Med. 2001;345:494-502.

7. Mehta SR, Yusuf S, Peters RJG, et al. Effects of pretreatment with clopidogrel and aspirin followed by long-term therapy in patients undergoing percutaneous coronary intervention: the PCI-CURE study. Lancet. 2001;358:527-533.

8. Wiviott SD, Braunwald E, McCabe $\mathrm{CH}$, et al. Prasugrel versus clopidogrel in patients with acute coronary syndromes. $N$ Engl J Med. 2007;357:2001-2015.

9. Cattaneo M. P2Y12 receptor antagonists: a rapidly expanding group of antiplatelet agents. Eur Heart J. 2006;27:1010-1012.

10. Husted S, van Giezen JJJ. Ticagrelor: The first reversibly binding oral P2Y12 receptor antagonist. Cardiovasc Ther. 2009;27:259-274.

11. Serebruany VL. Adenosine release: A potential explanation for the benefits of ticagrelor in the PLATelet Inhibition and Clinical Outcomes trial? Am Heart J. 2011;161:1-4.

12. Hammond JR, Stolk M, Archer RG, et al. Pharmacological analysis and molecular cloning of the canine equilibrative nucleoside transporter 1 . Eur J Pharmacol. 2004;491:9-19.

13. Van Giezen JJ, Sidaway J, Glaves P, et al. Ticagrelor inhibits adenosine uptake in vitro and enhances adenosine-mediated hyperemia responses in a canine model. J Cardiovasc Pharmacol Ther. June 22, 2011. [Epub ahead of print.]

14. Teng R, Oliver S, Hayes M, et al. Absorption, distribution, metabolism, and excretion of ticagrelor in healthy subjects. Drug Metab Dispos. 2010;38:1514-1521.

15. Gurbel PA, Bliden KP, Butler K, et al. Randomized double-blind assessment of the ONSET and OFFSET of the antiplatelet effects of ticagrelor versus clopidogrel in patients with stable coronary artery disease. The ONSET/OFFSET Study. Circulation. 2009;120:2577-2585.

16. Teng R, Butler K. Pharmacokinetics, pharmacodynamics, tolerability and safety of single ascending doses of ticagrelor, a reversibly binding oral P2Y12 receptor antagonist, in healthy subjects. Eur J Clin Pharmacol. 2010;66:487-496.

17. Husted S, Emanuelsson H, Heptinstall S, et al. Pharmacodynamics, pharmacokinetics, and safety of the oral reversible P2Y12 antagonist AZD6140 with aspirin in patients with atherosclerosis: a double-blind comparison to clopidogrel with aspirin. Eur Heart J. 2006;27:1038-1047.

18. Thebault JJ, Keiffer G, Lowe GD, et al. Repeated-dose pharmacodynamics of clopidogrel in healthy subjects. Semin Thromb Hemost. 1999;25 Suppl 2:9-14.
19. Zhou D, Andersson TB, Grimm SW. In vitro evaluation of potential drug-drug interactions with ticagrelor: cytochrome $\mathrm{P} 450$ reaction phenotyping, inhibition, induction, and differential kinetics. Drug Metab Dispos. 2011;39:703-710.

20. Brilinta prescribing information. Wilmington, DE: AstraZeneca; 2011.

21. Butler K, Teng R. Pharmacokinetics, pharmacodynamics, and safety of ticagrelor in volunteers with mild hepatic impairment. $J$ Clin Pharmacol. 2011;51:978-987.

22. Storey RF, Angiolillo DJ, Patil SB, et al. Inhibitory effects of ticagrelor compared with clopidogrel on platelet function in patients with acute coronary syndromes. J Am Coll Cardiol. 2010;56:1456-1462.

23. Gurbel PA, Cummings CC, Bell CR, Alford AB, Meister AF, Serebruany VL. Onset and extent of platelet inhibition by clopidogrel loading in patients undergoing elective coronary artery stenting: The Plavix Reduction Of New Thrombus Occurrence (PRONTO) trial. Am Heart J. 2003; 145:239-247.

24. Storey RF, Husted S, Harrington RA, et al. Inhibition of platelet aggregation by AZD6140, a reversible oral $\mathrm{P} 2 \mathrm{Y}_{12}$ receptor antagonist, compared with clopidogrel in patients with acute coronary syndromes. J Am Coll Cardiol. 2007;50:1852-1856.

25. Storey RF, Bliden KP, Ecob R, et al. Earlier recovery of platelet function after discontinuation of treatment with ticagrelor compared with clopidogrel in patients with high antiplatelet responses. J Thromb Haemost. 2011;9:1730-1737.

26. Plavix prescribing information. Bridgewater, NJ: Bristol-Myers Squibb/ Sanofi Pharmaceuticals Partnership; 2011.

27. Cannon CP, Husted S, Harrington RA, et al. Safety, tolerability, and initial efficacy of AZD6140, the first reversible oral adenosine diphosphate receptor antagonist, compared with clopidogrel, in patients with non-ST-elevation acute coronary syndrome. J Am Coll Cardiol. 2007;50:1844-1851. Erratum in J Am Coll Cardiol. 2007;50:2196.

28. Wallentin L, Becker RC, Budaj A, et al. Ticagrelor versus clopidogrel in patients with acute coronary syndromes. $N$ Engl J Med. 2009;361:1045-1057.

29. Steg PG, James S, Harrington RA, et al. Ticagrelor versus clopidogrel in patients with ST-elevation acute coronary syndromes intended for reperfusion with primary percutaneous coronary intervention. A Platelet Inhibition and Patient Outcomes (PLATO) Trial subgroup analysis. Circulation. 2010;122:2131-2141.

30. James SK, Roe MT, Cannon CP, et al. Ticagrelor versus clopidogrel in patients with acute coronary syndromes intended for non-invasive management: substudy from prospective randomised PLATelet inhibition and patient Outcomes (PLATO) trial. BMJ. 2011;342:d3527.

31. Cannon CP, Harrington RA, James S, et al. Comparison of ticagrelor with clopidogrel in patients with a planned invasive strategy for acute coronary syndromes (PLATO): a randomised double-blind study. Lancet. 2010;375:283-293.

32. Held C, Åsenblad N, Bassand JP, et al. Ticagrelor versus clopidogrel in patients with acute coronary syndromes undergoing coronary artery bypass surgery. Results from the PLATO Platelet Inhibition and Patient Outcomes Trial. J Am Coll Cardiol. 2011;57:672-684.

33. James S, Angiolillo DJ, Cornel JH, et al. Ticagrelor versus clopidogrel in patients with acute coronary syndromes and diabetes: a substudy from the PLATelet inhibition and patient Outcomes (PLATO) trial. Eur Heart J. 2010;31:3006-3016.

34. James S, Budaj A, Aylward P, et al. Ticagrelor versus clopidogrel in acute coronary syndromes in relation to renal function: results from the platelet inhibition and patient outcomes (PLATO) trial. Circulation. 2010;122:1056-1067.

35. Mahaffey KW, Wojdyla DM, Carroll K, et al. Ticagrelor compared with clopidogrel by geographic region in the Platelet Inhibition and Patient Outcomes (PLATO) Trial. Circulation. 2011;124:544-554.

36. Prevention of Cardiovascular Events (eg, Death From Heart or Vascular Disease, Heart Attack, or Stroke) in Patients With Prior Heart Attack Using Ticagrelor Compared with Placebo on a Background of Aspirin (PEGASUS). Available at: http://clinicaltrials.gov/ct2/show/ NCT01225562. Accessed September 23, 2011. 
37. Storey RF, Bliden KP, Patil SB, et al. Incidence of dyspnea and assessment of cardiac and pulmonary function in patients with stable coronary artery disease receiving ticagrelor, clopidogrel, or placebo in the ONSET/OFFSET study. J Am Coll Cardiol. 2010;56: 185-193.

38. Storey RF, Becker RC, Harrington RA, et al. Characterization of dyspnoea in PLATO study patients treated with ticagrelor or clopidogrel and its association with clinical outcomes. Eur Heart J. July 30, 2011. [Epub ahead of print.]

39. Storey RF, Becker RC, Harrington RA, et al. Pulmonary function in patients with acute coronary syndrome treated with ticagrelor or clopidogrel (from the Platelet Inhibition and Patient Outcomes [PLATO] Pulmonary Function Substudy). Am J Cardiol. September 3, 2011. [Epub ahead of print.]

40. Burki NK, Dale WJ, Lee L-Y. Intravenous adenosine and dyspnea in humans. J Appl Physiol. 2005;98:180-185.

41. Scirica BM, Cannon CP, Emanuelsson H, et al. The incidence of bradyarrhythmias and clinical bradyarrhythmic events in patients with acute coronary syndromes treated with ticagrelor or clopidogrel in the PLATO (Platelet Inhibition and Patient Outcomes) Trial. Results of the continuous electrocardiographic assessment substudy. J Am Coll Cardiol. 2011;57:1908-1916.

42. Serebruany VL. The TRITON versus PLATO trials: Differences beyond platelet inhibition. Thromb Haemost. 2010;103:259-261.

43. Kreutz RP, Stanek EJ, Aubert R, et al. Impact of proton pump inhibitors on the effectiveness of clopidogrel after coronary stent placement: the Clopidogrel Medco Outcomes Study. Pharmacotherapy. 2010;30:787-796.

44. Bhatt DL, Cryer BL, Contant CF, et al. Clopidogrel with or without omeprazole in coronary artery disease. $N \mathrm{Engl} \mathrm{J} \mathrm{Med.}$ 2010;363:1909-1917.

45. Warner TD, Armstrong PCJ, Curzen NP, Mitchell JA. Dual antiplatelet therapy in cardiovascular disease: does aspirin increase clinical risk in the presence of potent $\mathrm{P} 2 \mathrm{Y}_{12}$ receptor antagonists? Heart. 2010;96:1693-1694.

46. Serebruany VL. Aspirin dose and ticagrelor benefit in PLATO: fact or fiction? Cardiology. 2010;117:280-283.

47. Kirkby NS, Leadbeater PDM, Chan MV, Nylander S, Mitchell JA, Warner TD. Anti-platelet effects of aspirin vary with level of P2Y receptor blockade supplied by either ticagrelor or prasugrel. J Thromb Haemost. August 3, 2011. [Epub ahead of print.]

48. Momary KM, Dorsch MP, Bates ER. Genetic causes of clopidogrel nonresponsiveness: which ones really count? Pharmacotherapy. 2010;30:265-274

49. Malek LA, Kisiel B, Spiewak M, et al. Coexisting polymorphisms of P2Y12 and CYP2C19 genes as a risk factor for persistent platelet activation with clopidogrel. Circ J. 2008;72:1165-1169.

50. Hulot J-S, Collet J-P, Silvain J, et al. Cardiovascular risk in clopidogreltreated patients according to cytochrome P450 2C19*2 loss-of-function allele or proton pump inhibitor coadministration. A systematic metaanalysis. J Am Coll Cardiol. 2010;56:134-143.
51. Gurbel PA, Bliden KP, Butler K, et al. Response to ticagrelor in clopidogrel nonresponders and responders and effect of switching therapies. The RESPOND study. Circulation. 2010;121:1188-1199.

52. Tantry US, Bliden KP, Wei C, et al. First analysis of the relation between CYP2C19 genotype and pharmacodynamics in patients treated with ticagrelor versus clopidogrel. The ONSET/OFFSET and RESPOND genotype studies. Circ Cardiovasc Genet. 2010;3:556-566.

53. Wallentin L, James S, Storey RF, et al. Effect of CYP2C19 and ABCB1 single nucleotide polymorphisms on outcome of treatment with ticagrelor versus clopidogrel for acute coronary syndromes: a genetic substudy of the PLATO trial. Lancet. 2010;376:1320-1328.

54. Henriksson M, Nikolic E, Janzon M, et al. Long-term costs and health outcomes of treating acute coronary syndrome patients with ticagrelor based on the EU label - cost-effectiveness analysis based on the PLATO study [abstract]. Value Health. 2011;14:A40. Available from: http://www. astrazeneca.com/Media/Press-releases/Article/09052011-new-healthstudy-of-plato-brilique-with-clopidogrel. Accessed September 23, 2011.

55. Crespin DJ, Federspiel JJ, Biddle AK, Jonas DE, Rossi JS. Ticagrelor versus genotype-driven antiplatelet therapy for secondary prevention after acute coronary syndrome: a cost-effectiveness analysis. Value Health. 2011;14:483-491.

56. Claxton AJ, Cramer J, Pierce C. A systematic review of the associations between dose regimens and medication compliance. Clin Ther. 2001;23:1296-1310.

57. Effient prescribing information. Indianapolis, IN: Eli Lilly and Company; 2010.

58. Wiviott SD, Trenk D, Frelinger AL, et al. PRINCIPLE-TIMI 44 Investigators. Prasugrel compared with high loading- and maintenancedose clopidogrel in patients with planned percutaneous coronary intervention: the Prasugrel in Comparison to Clopidogrel for Inhibition of Platelet Activation and Aggregation-Thrombolysis in Myocardial Infarction 44 trial. Circulation. 2007;116:2923-2932.

59. Biondi-Zoccai G, Lotrionte M, Agostoni P, et al. Adjusted indirect comparison meta-analysis of prasugrel versus ticagrelor for patients with acute coronary syndromes. Int J Cardiol. 2010:150:325-331.

60. Mehran R, Rao SV, Bhatt DL, et al. Standardized bleeding definitions for cardiovascular clinical trials. A consensus report from the Bleeding Academic Research Consortium. Circulation. 2011;123:2736-2747.

61. The Cardiovascular and Renal Drugs Advisory Committee of the United States Food and Drug Administration. Prasugrel secondary review. Available from: http://www.fda.gov/downloads/AdvisoryCommittees/ CommitteesMeetingMaterials/Drugs/CardiovascularandRenalDrugs AdvisoryCommittee/UCM181185.pdf. Accessed September 23, 2011.

62. Mega JL, Close SL, Wiviott SD, et al. Cytochrome P450 genetic polymorphisms and the response to prasugrel: relationship to pharmacokinetic, pharmacodynamic and clinical outcomes. Circulation. 2009; 119:2553-2560.

63. Mega JL, Close SL, Wiviott SD, et al. Genetic variants in $A B C B 1$ and $C Y P 2 C 19$ and cardiovascular outcomes after treatment with clopidogrel and prasugrel in the TRITON-TIMI 38 trial: a pharmacogenetic analysis. Lancet. 2010;376:1312-1319.
Therapeutics and Clinical Risk Management

\section{Publish your work in this journal}

Therapeutics and Clinical Risk Management is an international, peerreviewed journal of clinical therapeutics and risk management, focusing on concise rapid reporting of clinical studies in all therapeutic areas, outcomes, safety, and programs for the effective, safe, and sustained use of medicines. This journal is indexed on PubMed Central, CAS,
Dovepress

EMBase, Scopus and the Elsevier Bibliographic databases. The manuscript management system is completely online and includes a very quick and fair peer-review system, which is all easy to use. Visit http://www.dovepress.com/testimonials.php to read real quotes from published authors. 